\title{
THE REGULATION OF TRANSPORT PRICE COMPETITION
}

\author{
MERRILL J. ROBERTS*
}

I

The Problem of Price Competition in Transportation

The social cost of transportation and the respective market roles of the several agencies are vitally influenced by rate regulation. Historically devoted to protecting the shipping public from railroad monopoly exploitation, the emphasis was altered by the advent of the newer agencies, and control is now significantly directed toward limiting price competition. Thus restricted, competition cannot perform effectively its basic functions of forcing innovation and efficiently channeling resources into alternative uses and to the most capable producers. With price competition stifled, the residual service competition exerts little pressure for cost-reducing innovation, but tends to be price-increasing and to deprive buyers of a range of price and quality choices.

On the other hand, price competition does not always function with the benevolence of the economist's model. With a large number of producers (as in agriculture), each can sell his entire output at the going market price, and there is no incentive to cut prices below this point. However, where producers are few, as in transportation markets, each can increase his sales and market share at the expense of his rivals by lowering prices. This policy is particularly attractive if one or all of the producers is burdened with high fixed costs that are unchanged by rather substantial changes in output. In such circumstances, competition may be "ruinous," driving prices of all producers to levels that permit none to achieve satisfactory financial results, despite the market's requirements for the output and buyers' perfect willingness to support the producers with higher prices. Here, the business ultimately goes to the rival with the largest resources, without regard for economic efficiency. In the case of industries like transportation which supply essential public services, such price behavior may require regulation to avoid these disastrous results.

The issues involved in interagency competition are complex. Market relations are complicated by the varying capabilities among the agencies in performing particular transportation jobs and by the industry differences in cost functions reflecting investment patterns. With privately-provided rights-of-way, the railroads require heavy investment per unit of output and have a high degree of fixed and sunk costs

* B.A. 1938, University of Minnesota; M.B.A. 1939, Ph.D. 1952, University of Chicago. Professor of Transportation, University of Pittsburgh. Formerly transportation economist with several federal agencies. Co-author [with T. C. Bigham], Transportation: Principles and Problems (2d ed. 1952). Contributor to economic journals on subjects emphasizing the economic implications of transport regulation. 
which are unrelated to volume of business. The motor and water carriers, employing publicly-provided ways for which charges are not assessed (water ways) or which are closely related to use (highways), have relatively low investment requirements and costs closely related to output. In addition, railroads require relatively large terminal investment and operating outlays which bear more heavily on the shorter hauls and produce interagency differences in cost variation with distance.

Interagency competition is further conditioned and complicated by prevailing pricing forms and institutions. Because of the heavy fixed investment, the railroads early developed a socially-sanctioned system of differential pricing, with contributions to overhead from various services determined by ability to pay. Although not socially justified by investment characteristics, the motor carriers followed this pricing pattern by matching the higher railroad rates, depending on superior service to attract business. Price competition is further affected by the practice of joint pricing through legally-sanctioned rate bureaus. ${ }^{1}$

The present system of control of interagency price competition is both roundly condemned and staunchly defended. Because of the overriding importance of transport services to the economy and the magnitude of the expenditures involved, there is a strong public interest in striking the appropriate balance between government control and market forces. Establishing rates at uneconomic levels by either regulation or the market may alternatively undermine the financial strength of the industries or inflate transport costs to the detriment of the public. In the complex setting of agency differentiation, discrimination, and price leadership, the issue of the appropriate roles of price competition and market forces, managerial initiative, and regulation has been drawn. This paper will describe and evaluate the present pattern of regulation as provided in the statutes and construed by the Interstate Commerce Commission, and then project the economic implications of free price competition in transport, with a view to reaching meaningful conclusions regarding the appropriate role of regulation.

\section{II}

\section{Regulation of Price Competition}

\section{A. The Control Pattern}

\section{The statutory background}

Basic to the control of competition in transportation are the general powers to regulate rates set forth in the Interstate Commerce Act. ${ }^{2}$ The ICC was endowed in rg20 with authority to set floors under rates to complement the existing power to establish upper limits. A rate could thereafter be unreasonable in violation of

\footnotetext{
${ }^{2}$ These cost and service-quality differences significantly distinguish competition among or between the agencies from competition among firms within an industry, and the rules that are appropriate for one do not fit the other.

${ }^{9}$ The Act embraces four parts, covering the various agencies: pt. I, 55 I-27, 24 Stat. 379 (1887), 49 U.S.C. $\$ \$ 1-27$ (1952) (railroad and pipeline carriers); pt. II, $\$ \$ 201-28,49$ Stat. 543 (1935), 49 U.S.C. $\$ 5301-27$ (1952) (motor carriers); pt. III, $\$$ 30I-23, 54 Stat. 929, (1940), 49 U.S.C. $\$ \$$ 901-23 (1952) (water carriers); pt. IV, $\$$ 40I-2I, 56 Stat. 284 (1942), 49 U.S.C. $\$ \$$ I00x-22 (1952) (frcight forwarders).
} 
section one of the Act if too low as well as if too high. But characteristic of such statutory provisions, establishment of criteria for determining reasonable minimum rates was left to the discretion of the administrative commission. Since no rules were provided for its application, its basic content has been drawn from other relevant statutory features.

Among the most important of such provisions is the rule of rate-making which stipulates that in prescribing rates, the Commission must consider the effect of proposed rates on the movement of traffic by the pricing carrier, the public interest in maintaining an adequate and efficient transportation service by the various modes, and the revenue requirements to insure such services. ${ }^{3}$ This rule focuses attention on the over-all revenues of transportation industries and provides for regulatory veto of managerial pricing decisions where the Commission's estimates of price elasticity of demand differ from those of the companies.

Crucial also to competitive price adjudication is the national transportation policy statement which prefaces the Act and establishes goals which condition the interpretation of all the substantive sections. The features of this statement most relevant for present purposes are the explicit congressional objectives to provide fair and impartial regulation of all modes, so as to recognize and preserve the inherent advantages of each; to foster sound economic conditions in transportation; and to maintain reasonable charges without unfair or destructive competitive practices. ${ }^{4}$ It is apparent that the Commission's interpretation of the key phrases "inherent advantages" and "unfair or destructive competitive practices" largely determines its exercise of power with respect to interagency price competition.

Two other statutory provisions are particularly relevant for rail-water competition. Section four, embracing the long-and-short-haul clause, requires prior Commission approval for railroads to discriminate by charging lower rates for longer hauls than for included shorter hauls..$^{5}$ A primary occasion for such discrimination is water competition at the more distant, but not at the intermediate, point. The statute requires, as a condition for approval, that the lower more distant rate be "reasonably compensatory." Under the Commission's administration, a reasonably compensatory rate must "be no lower than necessary to meet the competition" of the water carrier whose presence is the justification for the discrimination. ${ }^{6}$.The other provision, section 305 (c), stipulates that a water rate lower than a competitive rail charge shall not be construed as an "unfair or dẹtructive" competitive practice."

\footnotetext{
${ }^{3}$ The original rule of rate-making found in $\$ x_{5}$ a of the Interstate Commerce Act, 54 Stat. 912 (I940), 49 U.S.C. $\$ 15 a$ (I952), applies to railroads. Comparative provisions for the other agencies are found in §§ $216(\mathrm{i}), 54$ Stat. 924 (1940), '49 U.S.C. § 316(i) (1952) (motor carriers), 307(f), 54 Stat. 937 (1940), 49 U.S.C. $\$ 907$ (f) (r952) (water carriers), and 406(d), 54 Stat. 288 (r940), 49 U.S.C. § 1006(d) (I952) (freight forwarders).

54 Stat. 899 (1940). A complete discussion of the background and role of the policy statement is developed in S. C. Oppenhem, The National Transportation Policx and Inter-Carrier Competitive RATES (I945).

54 Stat. 904 (1940), 49 U.S.C. $\$_{4}$ (1952).

s Transcontinental Cases of 1922, 74 I.C.C. 48,71 (1922).

${ }_{54}$ Stat. 934 (1940), 49 U.S.C. $\$ 905$ (c) (1952).
} 


\section{Commission administration of competitive controls}

Since the pattern of competitive price regulation has been described in great detail by competent observers, ${ }^{8}$ a brief summary of the basic foundations underlying Commission policy will suffice. Although there is some wavering in the strength of controlling objectives, the Commission's approach to interagency competition is sufficiently consistent to sustain rather reliable generalizations. The basic approach is, in the main, a highly protective one, with manifest concern for the fortunes of the pricing carrier, his rivals, the system as a whole, and certain shipper groups.

Even under regulation, the right to set prices, including reductions when circumstances warrant, is a management prerogative. But reduced rates must not fall below a reasonable minimum as construed under section one of the Interstate Commerce Act. Reduced rates pass the test of reasonableness if they "are compensatory, do not cast an undue burden upon other traffic, and are not competitively unfair or destructive."

Determining whether a rail rate is compensatory is complicated by uncertainties regarding the appropriate contribution from each service to the large overhead. The Commission shows some ambivalence in these determinations, occasionally recognizing appropriately that rates above out-of-pocket costs but reflecting less than a pro rata share of overhead "may, because of the traffic they attract, make a greater contribution toward the indirect or constant costs than higher rates that would meet the full distributed costs."10 But the inherent suspicion of rates that fail to reflect a pro rata contribution is seen in the commonly-expressed view that ${ }^{11}$

... overhead costs are no less real than direct transportation costs and if all of the cars in the train, or any considerable number of them, are moving at submaximum rates, as must often be the case today, then clearly there is no room for application of the added traffic theory.

The permissible relationship between a rate and full costs is frequently tied to the value of the commodity, and rates well above this cost measure may be considered below a reasonable minimum.

${ }^{8}$ Particularly valuable is Ernest W. Williams, JR., The Regulation of Rail-Motor Ratr Competirion (1958). Others of note are Oppenhena, op. cit. supra note 4; U.S. Burend of Transport Economics and Statistics, ICC, Inter-Agency Rite Adjustasents, Rail and Motor (1956), and RaIL-Water Rate Adjusrments (I954); Langdon, The Regulation of Competitive Business Forces: The Obstacle Race in Transportation, 4I CORNell L.Q. 57 (1955).

${ }^{9}$ Hardware from New Britain to Chicago, 293 I.C.C. 515, 517 (1954).

${ }^{10}$ Petroleum Haulers of New England, Inc. v. Boston and Maine Railroad, 269 I.C.C. 6, 20 (1947).

${ }^{11}$ All Commodities, Less Than Carloads, Between Mainc, Massachusetts, and New Hampshirc, 255 I.C.C. 85,88 (I942). The reference to "sub-maximum rates" is not at all clear. Pcrhaps it refers to rates below the maximum of reasonableness under $\S$ I standards. If so, it loses sight of the fact that the market may impose lower ceilings, which the "added-traffic rates" may reflect. The identification of high- and low-cost carriers by reference to full costs is amply demonstrated by Commissioner Freas in a recent statement before the Seriate Committce on Interstate and Foreign Commerce. See Hearings Before the Senate Committee on Interstate and Foreign Commerce on S. 3778-Rate-Making Rule-ICC Act-to Amend the ICC Act so as to Strengthen and Improve the National Transportation System, 85th Cong., 2d Sess. 172 (1958). Professor Pegrum is also impressed by the Commission's strong attachment to full costs. See Pegrum, Do We Have a New Rule of Rate Making?, Traffic World, Fcb. 7, 1959, p. 52. 
Because of their relatively small overheads and the rather close correspondence between incremental and total costs, the Commission suffers less conceptual difficulty in determining appropriate cost references for water and motor carriers. According to an illustrative observation involving a motor-carrier rate proposal, ${ }^{12}$

It is well settled that an essential element to be considered in determining the reasonableness of a reduced rate is whether it would be reasonably compensatory; that is, return fully-allocated costs, plus a reasonable profit.

But the determination of the appropriate cost reference for testing the reasonableness of rail rates is not particularly crucial in any case. That the remuneration test is a necessary but not sufficient condition for approval is classically illustrated by this observation $:^{13}$

A showing that a rate is compensatory is not in itself justification for its establishment for the purpose of meeting competition; although compensatory the establishment thereof could constitute an unfair or destructive competitive practice. ...

Railroad rate reductions, accordingly, are not usually denied because found to be unremunerative, but because "competitively unfair or destructive." In this view, unfair or destructive rates are those "lower than necessary to meet the competition," a familiar phrase in the Commission lexicon, ${ }^{14}$ which means that they capture an inordinate share of the market. The bounds of decency are overstepped when a rival is denied a "fair share" of the market. As an illustrative application of the fair-share test, "the primary issue presented for our consideration is whether the rate proposed is lower than necessary for respondents to regain or to retain a fair share of this ... traffic."15

The determination of a fair share of the business is clearly indeterminate without reference to the very market forces which the Commission attempts to nullify. One obvious solution of the fair-share riddle sometimes adopted is rate parity. ${ }^{16}$ With rates equalized, shippers will assign their business on the basis of the respective capability of the rivals in meeting specific transport requirements. But with general agreement in shippers' calculus, rate equality may leave one rival high and dry. Accordingly, rate relationships reflecting service-quality differentials are common, ${ }^{17}$ with rail rates often below motor-carrier and above water-carrier charges. As might be expected in a system of rate differentials designed to compensate for service-quality disparities, the result often approaches an even split of the contested market, a division which, as the following statement suggests, appears to satisfy the Commis$\operatorname{sion}:^{18}$

${ }^{18}$ Iron and Stecl Between Philadelphia and Pennsylvania, 6I M.C.C. II3, II (1952).

${ }^{15}$ Gun Wad Felt-Newark, N.J., to Anoka, Minn., 293 I.C.C. 318,354 (1954).

14 Drawn from the tests of "reasonably compensatory" rates laid down by the Commission in cases involving long- and short-haul discrimination under $\$ 4$.

${ }^{16}$ Scrap Tobacco from Newark, N.J., to Selma, Ala., 293 I.C.C. 427, 428 (I954).

${ }^{10}$ WiLliass, op. cit. stipra note 8, at 44.

${ }^{18}$ Paper and Paper Articles from Canton, N.C., to Atlanta, Ga., 2I M.C.C. 89, 91 (1939). 
The traffic principally moves in volume quantities and in approximately equal proportions over rail and motor carriers alike.... Each type has succeeded in obtaining an equal share of the traffic, and, in the absence of a showing of any compelling disadvantage, we are not persuaded that a differential in rates is justified.

Perhaps because of innate bashfulness about allocating traffic, the controlling objective is sometimes described as relationships that provide each aspirant with "a fair opportunity to compete for the traffic," patently a difference in words rather than substance, since the failure to achieve what is regarded as a fair share automatically indicates a denial of this equality of opportunity. The Commission prescribes price relationships producing a specific traffic allocation just as effectively as if it assigned percentages and tried to establish rates that would validate them. ${ }^{10}$

Restraints on rates "lower than necessary to meet the competition" are designed in the interest of certain shipper classes as well as of rival carriers. This protective aspect of rate control occasions efforts to "maintain established rate structures" (another key phrase in the parlance of rate-floor administration) by imposing floors designed to preserve under competition the high discriminatory prices on valuable commodities established under railroad monopoly. This policy objective is classically illustrated in a case involving tobacco rates: ${ }^{20}$

While both rail and truck rates proposed may be reasonably compensatory, it is doubtful that they would contribute their fair share to the transportation burden considering the obviously high value of the traffic. To permit a further reduction by either form of transportation, or both, would only tend to increase still further the transportation burden on other traffic without giving due consideration to value of service on the traffic.

This review of Commission policy indicates an emphasis on competitive stability and on the preservation of over-all transportation revenues which is rooted in a basic conviction that unrestrained price competition would jeopardize financial stability and sacrifice the weak to the ravages of the strong. According to this view, the relatively low level of railroad out-of-pocket costs associated with the heavy overhead would permit the elimination from many markets, and maybe from business completely, of rivals who were more efficient in terms of all costs, including overhead. Financially sound transport companies are a necessary goal, but the salient features and underlying rationale of the control pattern suggest that the restrictive policies

\footnotetext{
${ }^{19}$ In the early postwar period, the Commission made a valiant cffort to free itself from the bog of protectionism in which it has sunk. The decision in New Automobiles in Interstate Commerce, 259 I.C.C. 475 (I945), has been widely hailed as a "leading decision," but in the light of subsequent developments, it hardly deserves that lofty title. In this case, the Commission stated that there is "no warrant for believing that rail rates, for example, should be held up to a particular level to preserve a motor-rate structure, or vice versa." Id. at 538 . The Commissioners still publicly subscribe to this doctrine; indeed, they could hardly do otherwise and even pretend to be seeking economic adjustments. See statement of Commissioner Freas, in Hearings, supra note II, at 165 . It will be noted that the quoted language in the New Automobiles case is strikingly similar to that in the rate-making rule as revised in the Transportation Act of 1958, 72 Stat. 568, 49 U.S.C.A. $\$ \$ 1231-40$ (Supp. 1958), and perhaps suffers the same ambiguity spotlighted in Commissioner Hutchinson's statement discussed below. See infra note 36 and text to which cited.

${ }_{20}$ Tobacco, North Carolina Points to Southern Points, 280 I.C.C. 767, 774 (195I).
} 
deemed necessary for revenue protection reflect rather novel interpretations of economic principles and yield highly questionable price relationships and economic results.

Rate reductions which the Commission thinks will sacrifice net revenues are denied, even though management construes the evidence to the contrary and regulatory techniques are ill-equipped to measure market reaction to specific prices. But even reductions unquestionably improving net income are apt to be found unlawful, and so the benefits of low costs are denied both to the carrier whose profits are restricted and to the shipping public through inflated rates.

This surprising and anomalous policy is based on control patterns which reflect unsound cost concepts and which improperly subordinate cost considerations to market-distribution criteria. Where costs are considered relevant, the Commission favors "fully-allocated" costs as the appropriate standard for rail rates. The economic objective of recovering overhead costs through the full array of prices does not dictate the reflection of some arbitrary pro rata share of overhead expense in any particular service, since a lower charge may yield even higher gross and net revenues. As will be elaborated below, it is a firmly-established economic principle that the significant measure for economic efficiency is incremental, or "direct," costs. Adoption of fullydistributed costs reflecting arbitrary overhead assignments leads to improper rate floors as well as to the faulty identification of low-cost and high-cost carriers. Even if Commission policies were closely oriented to cost considerations, they would frequently suffer from invalid economic content. ${ }^{21}$

The questionable policy of denying cost-justified reductions in the interest of some desired traffic distribution is apparently rooted in the injunction against "unfair or destructive competitive practices." Although an entirely worthy and necessary goal, the Commission's completely novel and unrealistic definition of this practice to embrace rates which increase net revenues thoroughly confuses the fruits of normal market competition with the ruinous consequences of destructive competition. The restrictive distinction between permissible reductions which simply meet competition and the undesirable ones which create $\mathrm{it}^{22}$ is speciously rationalized as necessary to. prevent a high-cost carrier from infringing unduly on the traffic of a more efficient competitor. ${ }^{23}$ But in practice, such limitations are not confined to the relatively few cases where the high-cost and low-cost agency have been specifically identified. In any case, such an identification would be meaningless where inappropriate cost measures are employed.

Denying the carrier the advantage of its relative costs creates a rate "umbrella" protecting its competitors. Although the Commission denies that its rate policies

31 As stated by Commissioner Freas, in Hearings, supra note II, at x68: "In many instances, however, the full cost of the low-cost form of transportation exceeds the out-of-pocket cost of another. If, then, we are required to accept the rates of the high cost carrier merely because they exceed its out-ofpocket costs, we see no way of preserving the inherent advantages of the low cost carrier." As indicated, the out-of-pocket cost provides the appropriate identification of the low cost carrier.

${ }^{33}$ Emphasized by Professor Pegrum, supra note-II, at 92.

${ }^{33}$ Statement of Commissioner Freas, in Hearings, stipra note $\mathrm{Ix}$, at $\mathrm{r}_{72}$. 
are designed to protect high-cost carriers, Professor Williams concludes that "regulation has consistently ... deprived the low-cost carrier of its cost advantage."24 The Commission's denial appears to reflect a rather specious distinction between motive and result, with the clear implication that rate policies may have this protective effect incidental to the pursuit of some other goal..$^{25}$ But if economic criteria are applicable (and the Commission does defend its policies on economic grounds), a goal requiring the collateral establishment of uneconomic relationships must be a poor one. Whether motive or result, the uneconomic results emerge when a more efficient carrier is prevented from asserting fully its advantage of low costs.

Insulating rates from relevant cost measures necessarily entails a price inflation that is intensified by tying rail charges to motor-carrier floors based on average costs that often quadruple the rail levels. Further inflation is introduced by establishing floors based on the high value-of-service rates born of rail monopoly. Where these rates significantly exceed motor-carrier average costs, the indicated result is redundant capacity in the motor-carrier industry or pressure for cost-increasing service requirements.

Present policies serve to protect over-all revenue levels (through high rate floors) and to preserve all competitors in specific markets (by traffic sharing). ${ }^{26}$ This approach establishes an umbrella for the whole system by efforts to render profitable any given level of investment in transport facilities, despite attainable reductions. This backward orientation toward historical investment and associated costs departs from the operation of the price system generally. It forestalls the fullest possible rationalization of the system and the elimination of such redundant capacity as may appear in response to the high rate floors, from investment mistakes, or from changed demand in specific market sectors.

\section{B. The Control Pattern as a Policy Issue}

The control pattern embracing the indicated features has been questioned by the railroads, which protest that the restraints are unjustly and uneconomically inimical to their financial interests; by shippers who deprecate the high rate floors; and by those independent students of transportation economics who feel that the allocation of traffic and resources is objectionable. It is supported, on the other hand, not only by the Commission, but by motor and water carriers and by some disinterested observers.

The doubts about regulatory policy were effectively articulated in the 1955 Report of the Presidential Advisory Committee on Transport Policy (often identified as the Weeks Committee or the Cabinet Committee), which emphasized the recent transition of transportation from a monopolistic to a highly competitive sector of the economy and the resulting obsolescence of a regulatory system that restricts instead of

24 Wristans, op. cit. supra note 8 , at 212.

${ }^{25}$ See Commissioner Hutchinson's statement, Traffic World, Nov. 29, r958, p. 38 .

${ }^{30}$ WillinMs, op. cit. supra note 8, at 2 ro. 
capitalizes on the competitive forces. ${ }^{27}$ The basic conclusion of the Report is that "in conformity with today's availability of a number of alternate forms of transport, Federal policies should be amended ... to permit greater reliance on competitive forces in transportation pricing. ...."2s

The Report struck directly at what the Committee saw as the statutory features that buttress the obnoxious competitive restraints imposed by the Commission. It proposed to delete the rate-making rule and to revamp the national transportation policy in order to eliminate the regulatory veto of managerial discretion in setting competitive rates; to encourage rate and service experimentation; and to permit the full reflection of cost advantages, so the market might rationally determine the appropriate role of each agency. The suggested policy statement deleted the reference to "unfair and destructive competitive practices" and substituted positive injunctions "to encourage and promote full competition between modes of transportation ..." and ${ }^{2 \theta}$

... to reduce economic regulation ... to the minimum consistent with the public interest to the end that inherent advantages, including cost and service advantages of each mode may be realized ... so as to reflect its full competitive capabilities.

Although no statutory test of appropriate rate floors was proposed, the language of the Report suggested that regulation should intervene only in situations where rates fell below direct costs.

In house hearings on the Report, the motor and water carriers strongly opposed: the proposals. According to the motor-carrier spokesman, the emphasizing of direct (or out-of-pocket) costs as the only statutory standard for minimum rates, as contemplated in the Report, invites ruinous competition and neglects other criteria of historical importance, particularly value of the service. In moving from value-ofservice pricing toward a greater cost emphasis, competition would force some rates. downward and thereby increase the burden on noncompetitive traffic and stifle the commerce of the country. In a competitive struggle, where rates gravitate toward out-of-pocket costs, the motor carriers would be victimized, since they have little noncompetitive traffic upon which to levy the costs of the competitive battle. Competition inevitably ends up in monopoly, with all shippers paying higher rates..$^{30}$.

In supporting the Report, the railroad spokesman emphasized the inequity and futility of existing restraints, since only one-third of intercity highway transportation. and one-tenth of inland water transportation is subject to regulation and can be

\footnotetext{
${ }^{27}$ Presidential advisorx Comm. on Transport Policy and Organization, Revision of Federal Transportation Policy, A Report to the President (1955). Space limitations require a brief and uncritical summary of the main relevant features of the Report. For excellent reviews, see Nelson, Revision of National Transport Regulatory Policy, 45 Axr. Econ. Rev. 910 (1955); Harbeson, New Perspectives in Transport Regulation: The Cabinet Committee Report, 52 Nw. U. L. REv. 490 (I954).

${ }^{28}$ Presidential Advisory Cosin., op. cit. supra note 27 , at iii.

${ }^{30} 1 d$. at 7 .

${ }^{50}$ Statement of James F. Pinkney, in Hearings Before a Subcommittee of the House Committee onInterstate and Foreign Commerce on the Report of the Presidential Advisory Committee on Fransport: Policy and Organization, 84th Cong., Ist Sess. 142-60 (1955).
} 
brought under comparable controls. But even in competing with regulated water transportation, the railroads suffer an unjustified disadvantage because of the onesided statutory provision that a water rate lower than a rail rate shall not be deemed an unfair and destructive competitive practice. Special disabilities are also involved in competition with regulated motor transport, since it is low rates based on railroad cost advantages, the only competitive avenue open, that are inequitably and uneconomically restrained. There are no comparable restraints on the full exploitation of the truckers' service-quality superiority. An interpretation of "unfair or destructive competitive practices" that requires the fair sharing of markets yields arbitrary and uneconomic apportionment of traffic by government fiat, depriving carriers of opportunities to reflect their inherent advantages. In both equity and economics, a "fair share" can only be what the carrier would get in a fair market test. The pricing freedom yielding these desirable results would not be detrimental to shippers of noncompetitive traffic, since rates would be reduced only with the prospect of an increase in net revenue which would lessen their burden of support. ${ }^{81}$

Identical bills implementing the general objectives and specific proposals of the Cabinet Committee Report were introduced in 1956 as H.R. 6raI and S. $1920 .{ }^{32}$ This legislation embraced the suggested change in the policy statement and, in addition, proposed a new rate-making rule aimed directly at the objectionable restraints by stipulating that in determining reasonable minimum rates, the Commission was not to consider their relation to the rates of, or their effect on, the traffic of any other mode of transportation or whether lower than necessary to meet competition. ${ }^{33}$ This legislation failed to come to a vote.

A senate committee investigation of the general financial problem of the railroads led to further consideration of the competitive pricing issue. Impressed with the unfavorable implications of regulatory policies for railroad revenues, the Committee on Interstate and Foreign Commerce recommended limitations on pricing restraints that became law in the Transportation Act of 1958 . $^{34}$ This Act modified the rule of rate-making, stipulating that "rates of a carrier shall not be held up to a particular level to protect the traffic of any other mode of transportation, giving due consideration to the objectives of national transportation policy declared in this Act." This compromise is less than the railroads wanted, but not so frightening to their competitors as the previous proposals, and apparently not particularly obnoxious to the Commission. ${ }^{35}$

\footnotetext{
${ }^{32}$ Statement of J. Carter Port, id. at ro7-42.

' ${ }^{32}$ Hearings Before a Subcommittee of the House Committee on Interstate and Foreign Commerce on Transportation Policy, 84 th Cong., $2 \mathrm{~d}$ Sess. (x956).

$33 \S 8$.

"Hearings Before the Subcommittee on Surface Transportation of the Senate Committee on Interstate :and Foreign Commerce on Problems of the Railroads, 85th Cong., 2d Sess. (1958). Sce also Senate Comm. on Interstate and Foreign Commerce, 85th Cong., 2D Sess., Pronlems of the Railroads, Report of the Subcommittee on Surface Transportation (Comm. Print. I958). Cf. 72 Stat. 568; 49 U.S.C.A. $\$ \$ 123 I-40$ (Supp. I958).

${ }^{30}$ Chairman Freas indicated during the course of the hearings that the Commission would not strongly object to a proposal closely resembling that which was passed." Hearings, supra note $\mathrm{Ir}$, at 183 .
} 
It is not at all clear that this legislation will occasion any sharp changes in the present approach, particularly in view of the remarkable insistence of the Commission that it does not hold up rates to protect the traffic of another carrier, a reflection of the subtle and shadowy distinction between protection as result and as motive. Commissioner Hutchinson publicly reiterated this view after the amendment became law, suggesting the innocuousness of the change by pointing out that the Commission does not ${ }^{36}$

require carriers to maintain rates at levels solely to protect competing carriers, although this may be the incidental effect ... of the discharge of our responsibilities under the National Transportation Policy.

This advance appraisal seems to square with the language of the amendment and with its first formal interpretation by the Commission. Since the proscription regarding the effect of a reduced rate on another mode is explicitly qualified by the policy statement injunction against "unfair or destructive competitive practices," the amendment can have little meaning without a drastically new interpretation of this crucial phrase, which appears to be unlikely. The Commission has already indicated that the new rule is but one of several statutory criteria to be applied in competitive situations, and is in no sense controlling. ${ }^{37}$

It appears that the elimination of the regulatory restraints that impede a truly market-oriented pricing system will require more drastic legislative action than has been undertaken. The present system of controls has many objectionable features that promote an inefficient allocation of traffic and resources and inflate transport costs. On the other hand, one cannot easily dismiss the conviction of the Commission, certain carrier interests, and others that existing controls are essential to sustain transport revenues at levels consistent with the services required by the economy. Inflated costs are preferable to the predicted breakdown of the system. Are the advantages of market-oriented prices attainable in transportation?

\section{III}

\section{Price Competition in Transportation}

Passing judgment on the economic issues posed by present control patterns requires a close examination of the kind of pricing behavior that might be expected to emerge in the absence of tight regulatory restraints. It is further necessary to compare this market-oriented model with the present alternative in order to determine whether the path of freedom or control yields superior economic results. Answers to the fundamental questions cannot be found in "the intent of Congress," but require reference to economic rather than legal criteria.

${ }^{80}$ Quoted in Traffic World, Nov. 29, 1958, p. 38. According to Commissioner Tuggle, the revised rule does spell the demise of "umbrella" rate-making. It is not clear, however, whether Commissioner Tuggle is also distinguishing motive from result. See id., Nov. 15, 1958, pp. 27-29.

${ }^{87}$ In a decision involving rail-motor competition for bulk petroleum products, cited in Railway Age, Feb. 23, 1959, p. 49. 


\section{A. Economic Concepts}

At the heart of the uncertainty regarding interagency competition is the determination of the appropriate relationship between prices and costs for the various agencies. And there is little hope of achieving meaningful areas of agreement on this question without firmly establishing the relevance for pricing purposes of the various cost measures. The basic distinction is between those costs that can and cannot be traced to particular units of output. As previously indicated, transportation parlance has generally settled on "out-of-pocket" costs to describe the former and "overhead" or "burden" to indicate the latter. It has also been noted that the addition of some arbitrary or pro rata share of the overhead to the out-of-pocket cost for a given block of output produces "fully-allocated" or "fully-distributed" costs. The out-of-pocket costs are thus incremental costs, since they are directly associated with the production of additional units of output.

At the core of social efficiency in resource use is the concept of incremental costs, which measure the value of the resources used up in providing output. Economizing scarce resources requires that additional units of output be worth more than the cost of producing them as measured by marginal costs, or the addition to total cost occasioned by some (very small) addition to output. It is significant that this optimizing goal is achieved without reference to those fixed or "overhead" costs that are unaffected in total by output changes. As Professor Samuelson puts it for the embryonic businessmen in economics principles courses: ${ }^{38}$

Let bygones be bygones. Don't look backward. Don't moan about your sunk costs. Look forward. Make a hard-headed calculation of the extra costs you'll incur by some decision and weigh these against the extra advantages. Cancel out all the good things and bad things that will go on anyway whether you make an affirmative or negative decision on the point under consideration.

Incremental costs, whether measured at the margin of output (which is extremely difficult in practice) or for larger increments through out-of-pocket costs, are crucial for interagency competition. ${ }^{39}$ For example, diseconomy will result from the expansion of motor-carrier investment for a production job that a railroad in being can perform, unless the decision to invest is made with reference to rail incremental costs. In market terms, the investment decision should hinge on relative prices

${ }^{38}$ Paut A. Samuelson, Economics 468 (1958). See his ch. 24 for an elucidation of the principles relevant here.

${ }^{39}$ For a discussion of the conceptual relationship between out-of-pocket costs as used in transportation parlance and marginal costs, see Wilson \& Rose, Out-of-Pocket Cost in Railroad Freight Rates, 60 Q. J. EcoN. 546 (I945). The term is often employed by the Commission to denote average variable cost of additional blocs of traffic. Id. at 549. Out-of-pocket cost will approach marginal cost only if the bloc of traffic involved is very small or if marginal cost is rather constant. This suggests that in the very possible case of rising marginal cost, out-of-pocket cost of larger traffic increments will be below marginal cost, and prices predicated on the former will be too low. This poses the practical problem of urgentlyneeded refinement in the concepts and techniques of cost measurement-a problem that is clcarly beyond the scope of this paper. We will employ the terms "incremental cost" and "out-of-pocket cost" with the implication of the best attainable cost measurement. In the specific analysis which follows, we assume away the problem by positing constant marginal costs, a simplification which does not affect the principles adduced. 
which reflect the respective outlays associated with each alternative. The appropriate measure on the railroad side is out-of-pocket costs. In the interests of social efficiency, the investment should not be made unless the motor carrier would get the business at a price covering all costs (including investment costs, which are in this case "incremental") in competition with a rail rate as low as out-of-pocket costs. As this illustration suggests, sterilization of this cost measure nullifies a crucial investment guide.

Letting bygones be bygones supports the economic logic of equating all transport prices to marginal costs, as has been proposed by some students of welfare economics. ${ }^{40}$ But for the railroad industry, which is characterized by large fixed overheads, this pricing policy would leave some costs uncovered and necessitate subsidy if society is to have the services it requires and is willing to pay for. Subsidies to cover overhead are questionable on equity grounds and are probably not politically feasible. An economically defensible alternative is differential pricing, which has historically characterized railroad rates (and which has been adopted, to a large degree, by motor carriers, despite insignificant overheads). The overhead is assessed to particular services on the basis of demand considerations; those services with the least elastic demands bear the highest rates relative to incremental costs. ${ }^{41}$ This pricing system has the virtue of encouraging utilization of railroad fixed facilities, the costs for which are sunk, and permitting full or maximum coverage of the overhead.

Although the roots of differential pricing lie in monopoly, the rise of interagency competition does not spell its demise by driving all rates to the level of average total costs. Since motor- and water-carrier services are not uniformly substitutable for those of the railroads, railroad demand functions retain some elasticity differentiations. Interagency competition thus occasions a modification in the pattern of discrimination by driving rates downward (and some more than others), but not its elimination. In competitive situations, rates will commonly gravitate toward the costs of the rivals, rather than toward those of the railroads themselves.

The foregoing considerations suggest that the concept of "fully-allocated" or "fully-distributed" cost is economically sterile for railroad pricing and no less so for the other carriers, although the small overheads take it less far from the mark. It is apparent that overhead costs per output unit are price-determined and not pricedetermining. The overhead element per unit varies inversely with volume, which, in turn, is a function of price. It is, therefore, a meaningless product of circular reasoning to establish as a norm for railroad rates a sum composed of unit out-of-

\footnotetext{
${ }^{40}$ See, e.g., Hotelling, The General Welfare in Relation to the Problems of Taxation and of Railway and Utility Rates, 6 Econometruca 242 (1938).

¿ Professor Merton Miller is critical of railroad discrimination, identifying cases where shippers assessed high discriminating rates would pay less, not more, under uniform monopoly pricing. Miller, Decreasing Average Cost and the Theory of Railroad Rates, 2 I So. Econ. J. 390 (r955). As will be apparent, the pattern of differential pricing which would emerge from the principles advocated in this paper departs markedly from the third-degree monopoly discrimination with which Miller deals. The former specifically contemplates that competitive forces should press down these high rates; if not, they should be reduced by regulation.
} 
pocket cost plus a pro rata share of the overhead. In the interests of revenue conservation, a company must add to out-of-pocket costs an amount which reflects demand conditions and commonly produces a price either more or less than the amount given by a mechanical statistical allocation of the overhead burden. ${ }^{42}$ In many circumstances, a rate lower than the fully-distributed costs yields a greater total contribution to profit than one which equates with this statistical allocation. The Commission's observations that "the overhead costs are just as real as direct costs" and that "the overhead contribution must come from somewhere," with the direct implication that rates below fully-distributed costs deplete net revenue, may be good law, but they are poor economics.

\section{B. A Model of Competitive Pricing in Transportation}

Regulation has restrained the adjustment of differential pricing to the new market conditions associated with the rise of interagency rivalry by holding rates higher than they would be otherwise. This raises the fundamental question whether an economically meaningful equilibrium of prices can be established without the kind of restraints presently exercised. It is the position of this paper that a realistic application of economic principles indicates that, with certain reasonably attainable conditions, such an equilibrium can be achieved. ${ }^{43}$

The first essential condition is that the market rivals act rationally to pursue company interests by endeavoring to maximize profits or net revenues. The path leading to maximum profits is depicted in elementary terms in chart one, which shows a negatively inclined demand curve (DD) and the derived marginal revenue curve (MR). (Following the previous definition of marginal costs, marginal revenue is the addition to total revenue associated with an increment of sales. $)^{44}$

It is apparent that profits are highest from sales at output $(Q)$ and price $(P)$, where marginal revenue equals marginal cost. To the left of that point, additional sales add more to revenues than to costs. (The marginal revenue curve lies above the marginal cost curve.) To the right of that output (where marginal revenue is below marginal cost), additional sales add less to revenue than to cost and subtract from total profits.

42 Determination of the appropriate cost reference is plagued not only by the conceptual differences and expectable quantitative gaps between marginal costs and commonly-employed measures of out-ofpocket costs, referred to in note 39 supra, but also by the distinction between long run and short-run out-of-pocket levels. This, too, represents a problem of cost measurement and application that is not crucial for our analytical purposes. However, it is worth noting that the out-of-pocket measures produced by the Commission's costing staff reflect long-run conditions and thus embrace the full investment requirements imposed by output expansion over extended periods. While the interests of both the firm and society require that long-run prices recover such costs, a case can be made for reflecting in price shorter-term out-of-pocket costs in the face of short-run excess plant capacity if demand conditions requirc. The feasibility of such departures from long-run requirements depends on the degree of price flexibility permitted by market, institutional, and regulatory forces.

${ }^{8}$ The applicability of the assumptions required for stability is more closely examined below.

"For analytical simplicity and to equate marginal and out-of-pocket costs, this chart and the follow. ing analysis employs constant marginal cost. The influence of different cost assumptions will be considered below. 


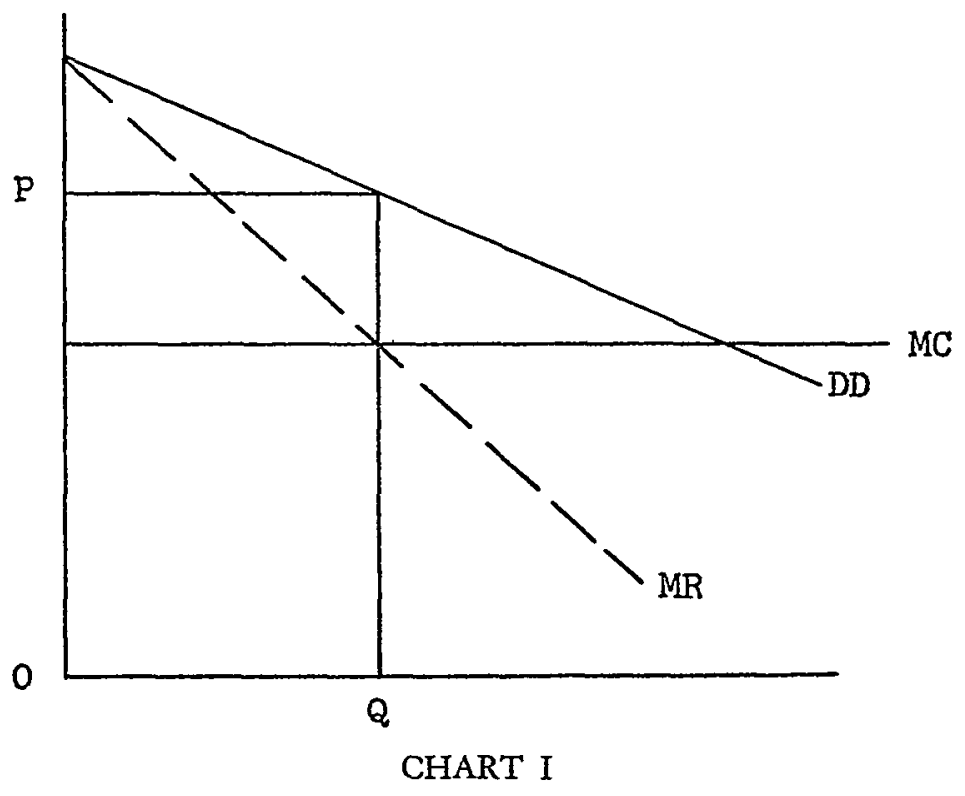

Goals alternative to profit-maximizing include securing the largest possible share of the market or the highest sales (gross revenues) consistent with some acceptable profit level. Chart one suggests that the probable result of pursuing these alternative objectives is a price lower than dictated by maximum profit and a tendency to drive prices down to marginal costs.

Equilibrium also depends in some cases on traditional demand functions, under which the pricer can sell progressively more at successively lower prices, with the rival's price fixed at a certain amount. This condition is violated by a market embracing only one buyer who does not share his traffic in some proportion depending upon relative prices, but insists on allocating all to one or the other. In some cases, "all or nothing" markets may create competitive instability, since, with any given price relationship, one rival is foreclosed from the market. Each competitor has, therefore, every profit incentive to reduce prices to get the business, and successive retaliatory reductions may take rates down to the lower direct costs of the two rivals. As will be indicated, the effect of such markets on stability depends on the comparative service qualities and the margin between the direct costs of the competitors.

A further requirement for the realization of the pricing relationships developed in the model is a working knowledge of the basic facts on which the optimum depends, including costs, market size, potential shipper reaction to various pricing relations (demand functions), and rivals' pricing limits as measured by direct costs.

The kind of pricing patterns that might be expected in free transport markets will reflect the limited number of sellers, representing the economist's condition of oligopoly. Most commonly, pricing authority is lodged in the rate bureaus of the competing agencies, and the markets are more appropriately characterized as duo- 
polistic. The following models are based on the duopoly case. Departure from duopoly resulting from the intrusion of the competition associated with independent pricing action and with proprietary and exempt transportation would alter the maximizing references and produce lower prices than indicated, but would not prevent an equilibrium adjustment at nonruinous levels. If an oligopolist (or duopolist) attempts to increase his sales and revenues by reducing prices, he may invite retaliation (matching reductions), with the market shared as before, but at lower prices and possibly smaller revenues. Under these circumstances, price behavior is highly dependent on the firm's assumptions regarding his rivals' responses to his initiative. ${ }^{45}$ The duopolistic rivalry portrayed reflects the assumption that reductions will be initiated when it appears that they will be profitable even with retaliation. (They will, of course, be even more profitable without retaliation). Consistent with the profit-maximizing motive, it is further assumed that the rival will retaliate only within the limits imposed by his cost and demand functions. Retaliation is not equated with "matching reductions" because of the previously specified interagency variation in demand and cost relations. Some market situations will be noted where profit interests dictate the advisability of "sitting tight" in the face of expected retaliation. ${ }^{46}$ There seems to be substantial empirical support from postwar pricing history in transportation for the retaliation assumption.

The competitive models presented reflect several simplifying conditions. One is that the rivals are confronted with a market represented by a fixed number of tons tendered per time period. This simplification overlooks the potential expansion of the total market with lower prices from the increased sales of shippers affected by the reduction, either through increased purchase of the product or the attraction of business from other producers. But the latter occasion would probably induce corresponding rate reductions from these competitive sources to common markets precisely to forestall this development, and the former is not apt to be important, particularly for the high-grade manufactured articles that are at the center of rail-motor price competition. To the extent that the total market would be enlarged by reductions, the fixed-size assumption understates the gross and net revenues associated with lower rates and inflates the equilibrium price. (In terms of profit-maximizing apparatus, the equilibrium position would be moved to the right.) This force, however, would not vitiate the competitive stability described.

The second simplifying condition is constant incremental (out-of-pocket) cost over the relevant ranges of ouput. In the likely case of rising costs, ${ }^{47}$ the profit advantage of lower rates would be curtailed. (In graphic terms, the equilibrium position would

\footnotetext{
45 For a general discussion of duopoly and oligopoly, see George J. Sticher, The Theory op Price chs. 12-14 passim (1946).

${ }^{10}$ These cases are of no concern for minimum rate control, but may represent problems for maximum rate regulation because of their similarity to the monopoly exactions associated with duopolistic collusion. This problem will be considered in more detail below. Tacit collusion may represent a greater problem in transport markets than in industry generally, since the high prices do not have to be "achieved," but have actually been enforced and stabilized by government sanction in many cases.

${ }^{47}$ See Wilson \& Rose, supra note 39 , at $557-58$.
} 
shift to the left.) Recognition of increasing incremental costs does not undermine competitive stability, but indicates a higher equilibrium price. In general, the two simplifying conditions are mutually offsetting.

According to the following analysis, the goal of profit-maximization, coupled with a disposition of the market progressively to alter the division of business between rivals in accordance with their price relations, permits a stable price equilibrium at levels not ruinously encroaching on direct costs, but below the high discriminating monopoly prices originally established by the railroads. This equilibrium derives from the fact that the cost of expanding output and sales at the expense of a competitor soon exceeds the gain, since the lower prices that achieve this expansion must also be accorded to present customers who are willing to pay more.

The hypothetical cases developed represent some well-known cost and demand relations associated with rail-truck competition, but the underlying principles should be equally applicable to rail-water rivalry. In case one (table one), it is assumed that the railroad (or railroads in the case of oligopoly with joint pricing) has lower direct costs (seventy cents compared with ninety cents per hundred pounds), but that the motor carrier offers a preferred service, so that equal prices will yield the railroads very little of the business. The total market is represented by $\mathrm{r}, 000$ tons per time unit.

Because the services are substitutes, the sales of each rival will be a function of the other's price. As shown, if both competitors charge one dollar per hundred pounds, the railroad will handle roo and the motor carrier 900 tons. Assuming the motor-carrier rate remains fixed at that level, the railroad can increase sales to 150 tons at a rate of ninety-five cents, to $25^{\circ}$ tons at ninety cents, and so on.

Similarly, with a rail rate of one dollar, the motor carrier can pre-empt the market by cutting to ninety-five cents. The table also shows the contribution to profit (the excess of associated revenues over associated costs) attributable to each price and volume combination. For example, the roo-ton rail output at the one-dollar rate yields a net of thirty cents per hundred pounds, or a total of $\$ 600$; whereas $25^{\circ}$ tons at ninety cents yields a total of $\$ 1,000$.

With the motor-carrier rate held at the initial \$1.00 level, the railroad can increase its net contribution from $\$ 600$ to $\$ 1,700$ by cutting to eighty cents. Truck net, which falls from $\$ 1,800$ to $\$ 300$, can be restored to $\$ 45^{\circ}$ with a ninety-five-cent rate, reducing rail volume from $85^{\circ}$ to 550 tons and contribution from $\$ 1,700$ to $\$ 1,100$. With this market distribution, neither rival has any further reducing incentive, and true equilibrium is established at a nonruinous level, with each sharing in the market. The cost and demand relations portrayed in this case are representative of the significant market sector embracing medium-distance hauls of truck-load quantities, where the railroads may be expected to have lower incremental costs and the trucks a preferred service.

As illustrated in case two (table two), a sufficient incremental cost advantage not offset by compensating service advantages may permit the low-cost carrier to profitably pre-empt the market. In this instance, the out-of-pocket costs are again ninety 


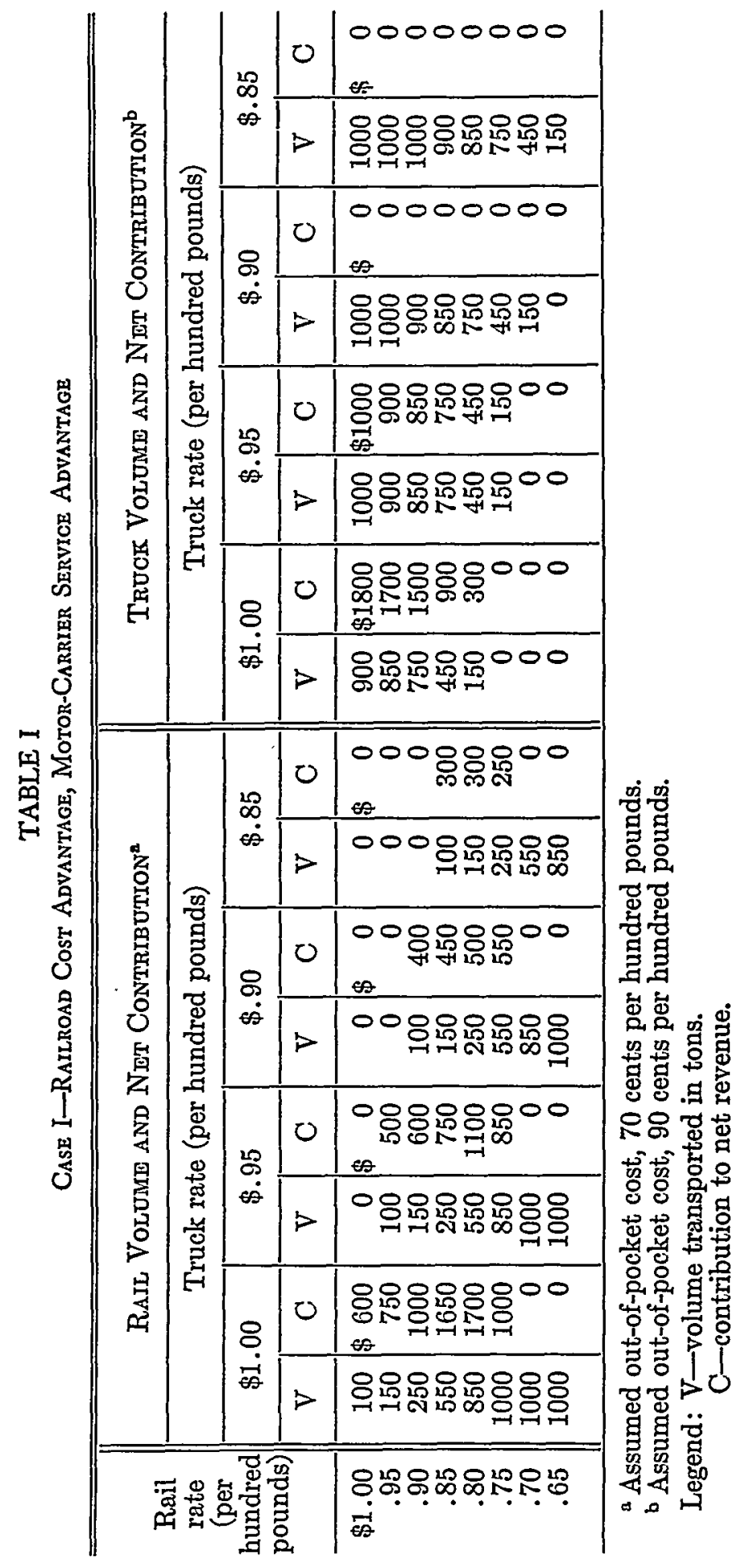


Transport Price Compretition

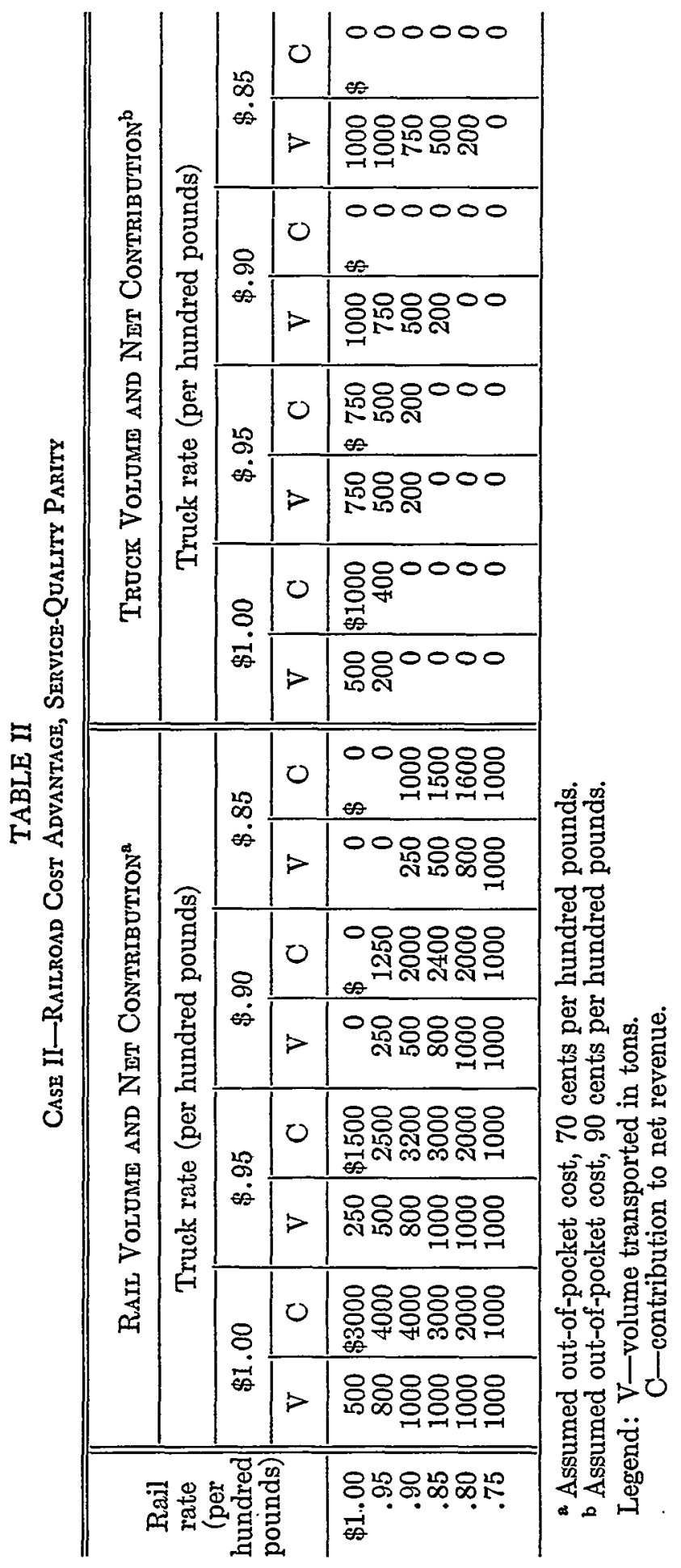


cents for rail and seventy cents for truck; but at rate-parity, the market will be evenly divided. By cutting from one dollar to ninety-five cents, the rail volume can be increased to 800 tons and the associated contribution advanced from $\$ 3,000$ to $\$ 4,000$. This action, however, reduces truck volume to 200 tons and contribution to $\$ 400$; but by cutting to ninety-five cents, the original division will be restored and a revenue contribution of $\$ 500$ salvaged. But the indicated railroad response to the resulting decline of contribution to $\$ 2,500$ is another drop to ninety cents, which pre-empts the bulk of the market and increases contribution to $\$ 3,200$, more than initially realized. This case is representative of long hauls of truck-load quantities, where services are often comparable, but railroad costs are lower. The same result (pre-emption) is to be expected with equivalent costs and significant service disparities, and particularly with cost and service advantages working in the same direction. A likely example is short hauls of truckloads, and especially less-than-truck-load shipments.

These two cases have included either or both cost or service disparities. Even with equality in these factors, however, a market system can produce a unique price relationship that maximizes for both rivals at levels significantly above incremental costs. In case three (table three), the market is shared equally at any identical price for both competitors whose incremental costs are eighty cents per unit. At the onedollar rate, each can improve net revenues (assuming the rival's price is fixed) by cutting his price to ninety=five cents. If one cuts and the other then follows, each will realize a $\$ x, 500$ contribution to net, and neither can improve his position by a further reduction, whether matched or not.

According to these illustrations, the price aggressor may or may not be better off with the rates and revenues yielded by the equilibrium than with higher rates. In case two, the railroad profits more at the equilibrium rate, netting $\$ 3,200$ instead of $\$ 3,000$. The margin of profit of the equilibrium rate over the initial rate is even greater in case one. In case three, representing cost and service equality, however, the intial one-dollar rate produces $\$ 2,000$ net, while the ninety-five-cent rate yields only $\$ 1,500$. In the circumstance represented by cases one and two, the railroad's assumption regarding the rival's price policy is immaterial, since it will be better off even with retaliation. But if the initial price is high enough, active competition is unprofitable. For example, if the original rate in case two had been $\$$ r.15 instead of one dollar, the 500-ton output at a margin of forty-five cents would yield a net of $\$ 4,500$, higher than realized at any lower price, with or without retaliation. Even in case one, it would be necessary to assume an original price of only \$r.30 instead of one-dollar to occasion a higher yield from the roo-ton share $(\$ 1,200)$ than from the $55^{0-t o n}$ share at the equilibrium price (yielding $\left.\$ \mathrm{r}, 100\right)$. This $\$ 1,200$ net can be exceeded only in the unlikely event of unmatched reductions to eighty or eighty-five cents. So with perfect knowledge of the market and the expectation of retaliatory price cuts limited only by the rival's out-of-pocket costs, the railroad, as well as the motor carrier, would do well to sit tight. This case clearly is of no interest for minimum rate control. 
Transport Price Competition

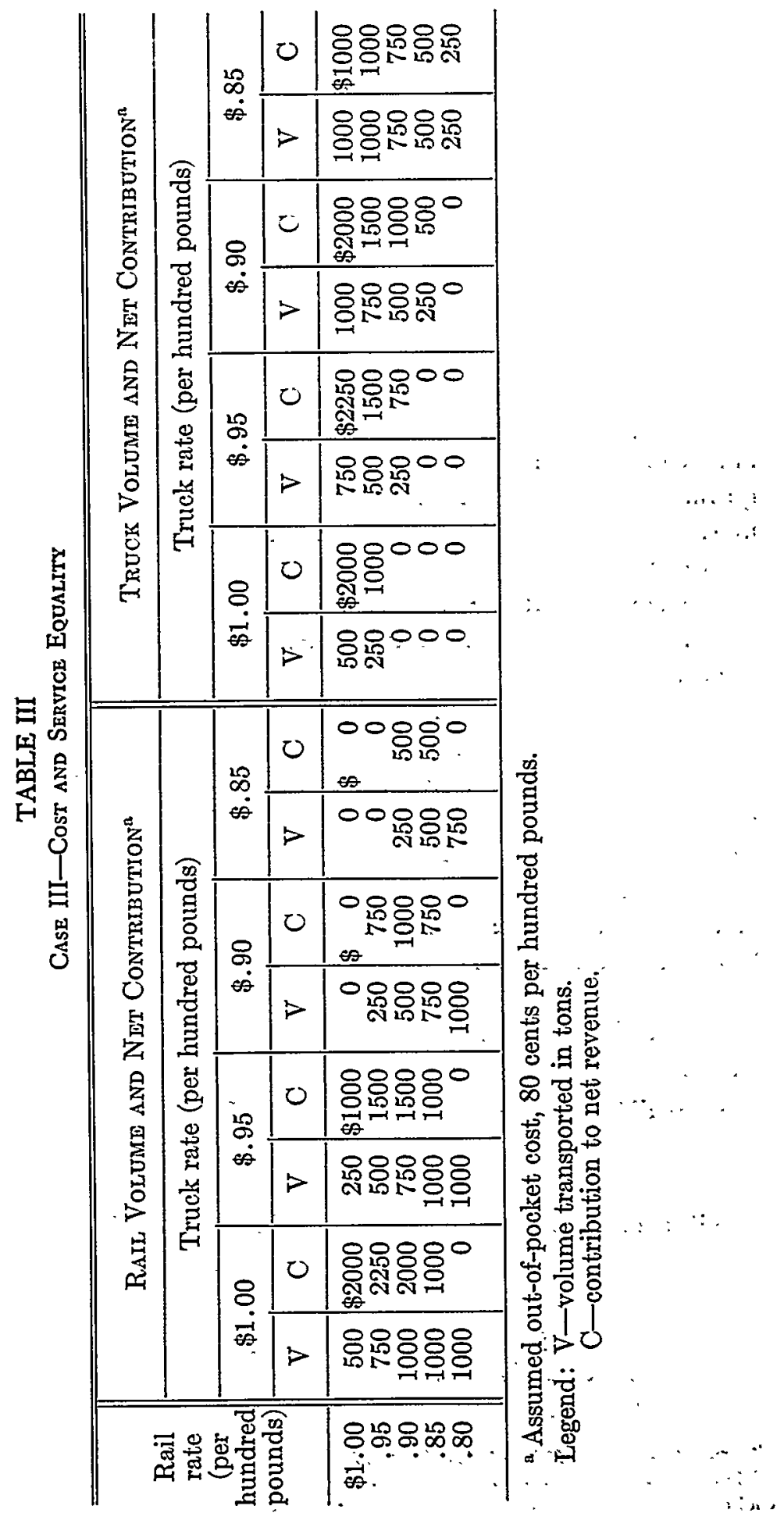


There is always the possibility, however, that reductions will be set in motion through inadequate knowledge or the pursuit of nonmaximizing goals. In the Commission's view, a reduction of the rail rate from $\$$ r.30 to the ninety-cent equilibrium price in case one represents a "needless sacrifice of revenue." But before characterizing reductions toward the equilibrium as "destructive" and "eroding revenues" in some way inimical to the public interest, consideration should be given to the fact that these high discriminating monopoly prices originally established by the railroads can be maintained under competition only by tacit duopolistic collusion. ${ }^{48}$ Since a "normal" return is precisely that which is realized under competition, there is no apparent justification for continuing these monopoly exactions.

The pricing system described embraces the following salient features:

r. A highly significant characteristic of the price relations is a stable equilibrium well above direct costs for at least one rival. Notably absent is the disorderly gravitation of prices for all producers that spells ruinous competition. This historically-illustrated competitive characteristic associated with the railroads' high fixed costs need not arise when railroads (acting collectively) compete with another mode. Nor are the price instabilities noted in the motor-carrier industry in its infancy period and during the depression of the 1930's relevant for motor-rail competition.

2. This pricing system contemplates that each agency will maximize its net revenues within the limits imposed by its cost levels and service capabilities relative to other rivals in the market. It is market-oriented, since each rival gets no more and no less than the market will accord it in terms of its evaluation of the worth of the services performed.

3. This system departs rather sharply from the price relationships prevailing under regulation. The rates would be generally lower than administrative price floors, ${ }^{49}$ although in markets with very high rates, tacit understandings could forestall reductions. Some market-sharing would remain, but with different price relations and empirical shares. Unlike regulation, it contemplates pre-emption of markets by one rival where cost and service relations so dictate, possibly with revenues greater than realized with the market shared at higher prices.

\section{Economic Validity of the Pricing Pattern}

Modifications in price relations along the lines suggested would substantially alter traffic allocation. Such shifts spring inevitably from the basic difference in concept of market-oriented and administratively-determined prices. The market is impartial as among alternative producers, tapping for a given job that one which can provide transport service of a given quality at the lowest price. Regulation, on the other hand, can scarcely avoid introducing a bias. This is well illustrated in case one, where

\footnotetext{
${ }^{48}$ STIGLER, Op. cit. supra note 45 , at $269-77$.

${ }^{48}$ For an analysis of the price-increasing aspect of price floors imposed under California regulation, sec Nicholson, Motor Carrier Cost and Minimum Rate Regulation, 72 Q. J. EcoN. 139 (1958).
} 
the motor carrier prefers prices equalized at one dollar to any other adjustment shown. The railroad, on the other hand, profits most by charging eighty cents in combination with a one-dollar motor-carrier rate. But according to market dictates, the best the competitors can mutually do is a rail rate of eighty cents and a motorcarrier rate of ninety-five cents. Imposing any other relationship must arbitrarily favor one or the other by holding the rail rate above eighty cents or the truck rate above ninety-five cents, in direct violation of "impartial" regulation.

Although it is impossible quantitatively to assess the traffic shifts that might be associated with competitive pricing, movements both ways between the rail and nonrail carriers would probably result. It is extremely likely, however, that the balance would favor the railroads, with the substitution of market-oriented prices that reflect railroad costs for an administered system that stifles them. Although not equated with incremental costs as in a perfectly competitive market, the rates are deeply rooted in this highly relevant cost measure. Lower prices would commonly be associated with lower direct costs and traffic channeled to the low-cost carrier, unless (and to the extent that) quality considerations reflected in market evaluations should override the cost differential. This is the expected orientation in the operation of the price system in the economy generally. More expensive alternatives are purchased accordingly as their superior quality is evaluated in the market. Producers combining higher quality with higher costs can survive; those associating lower quality and higher costs cannot. There seems little question that the alteration described would promote a more economic traffic allocation. ${ }^{\mathbf{5 0}}$

In addition to the traffic shifts, over-all prices will generally be lower than under the present pattern, but certainly not at levels that could be considered "ruinous." Although lower rates clearly benefit affected shippers (and, hopefully, consumers of the end products), the problem of compensating increases on other traffic must be considered. ${ }^{\text {[1 }}$

Although apparently overlooked by the Commission, the concern about compensating increases, based on considerations of overhead support for a large fixed plant, must have little relevance for the nonrail carriers where a rather intimate adjustment of firm size and output is possible. The railroads presumably maintain the rates in question at relatively low levels because they are more profitable than higher charges would be. For example, coal is so favored because of rather elastic transport demands dictated by the high ratio of rates to final price in combination with the substitution potential of alternative energy sources. Where the lower rates are at maximizing levels predicated on such market conditions, it would be quite fruitless to raise them simply because others had been lowered. Nor would any

\footnotetext{
50 The system of allocating traffic is not consistent with that envisioned by those who advocate regulatory establishment of rate differentials based on cost differences. See, e.g., Hultgren, The Nature of an Economical Division of Traffic, in Transportation and National Policy 129 (I942). Such price relationships, however, are not market-oriented and could be maintained only by government fiat. It seems, however, to resemble that envisioned, among others, by Professor Pegrum, as reflected in supra, note $I x$, and in other writings.

"1 We are not concerned herc with rates below direct costs, which should be increased in any case.
} 
directly-related occasion arise to raise them in the general case where reductions would increase traffic volume and net revenues. With the profit-maximizing goal and workable market knowledge, reductions from the only monopoly levels which decrease net would probably be relatively rare and thus overbalanced by the gains.

However, regardless of this balance and quite independent of contemplated reductions, there is a strong case for raising rates which are below net-maximizing levels, unless over-all earnings are considered excessive; such charges do "cast a burden on other traffic" and contribute to the presumed need to maintain the high discriminating monopoly rates. Obviously, this does not imply rates on low-grade commodities that will stifle their movement; low "ability to pay" will be correlated with relatively low maximizing rates. It does, however, question the special treatment arbitrarily accorded some traffic without reference to the generally-governing cost and demand relationships.

Although not conceivably working an injustice on other shippers, the competitively-induced rate reductions would probably shrink the total amount spent and the total support provided by society for transport activities at present output levels. It should be apparent, however, that a decrease in total outlays does not necessarily bring the "inadequate transport system" that so worries the Commission. It is not a question of "starvation wages" for the existing system, since over-all cost savings from more efficient traffic distribution would reduce support requirements. This is illustrated in case one, where the distribution associated with the initial matched price of one dollar (assumed to be administratively fixed) incurs total direct costs for the two carriers of $\$ 7,600$, well above the $\$ 15,800$ associated with the equilibrium adjustment.

But aside from such cost savings, market-oriented prices carry no guarantee that the revenues realized by any firm or agency will support any particular level of past investment. Such transport prices, like those in the economy generally, are essentially and appropriately forward- and not backward-looking. Utilizing public authority to exact revenues to support fully any given level of plant investment is to put the shoe on the wrong foot. Rather, the revenues realized from market-oriented prices provide the essential and only reliable guide to appropriate investment levels. There is little reason to distrust as inherently inadequate the economy's support for transportation dictated by competitively maximizing prices. As in other sectors of the economy, the market will support the transport services it requires.

Although present volume could doubtless be efficiently accommodated by smaller plant investment, the indicated adjustment would probably in practice be effected by reduced investment requirements for future output levels associated with the general economic growth. But it is desirable to consider the extreme case of actual contraction in order to clarify the principles.

The rule of market support from forward-looking prices applies as much to railroads as to the other agencies, despite the high fixed costs of the former. Failure to realize full support for existing investment levels calls for sloughing-off marginal 
facilities and for financial rationalization to bring capital structures and associated capital costs in line with earnings potential. ${ }^{52}$

But, as indicated, the adverse competitive impact would probably fall on the motor and water carriers which are not in any sense uneconomically or inequitably disadvantaged by reduced rates that are profitable to the railroads. Rather, equity as well as social efficiency requires full exploitation of the relatively low railroad direct costs. Failure to do so by imposing price floors unrelated to costs spells overinvestment in nonrail facilities and redundant transport capacity. The employment of public authority to perpetuate the resulting windfalls is hardly warranted by equity or economics. Transportation companies cannot reasonably be exempted from the risks of defeat that are an inevitable aspect of playing the economic game under the impartial rules of competition.

A readjustment in transport investment, which might take the form of either or both fewer or smaller firms, carries no serious threat to the public welfare. Clearly no real diseconomy results from fewer firms in any industy nor from smaller ones in these industries. Since motor carriers particularly are characterized by the absence of scale economies, companies do not have to be big to be efficient or profitable and relatively small total demands can be recognized by forthcoming capacity supply. ${ }^{\mathbf{3}}$ Even presently-specialized motor-carrier services (such as those of the petroleum haulers) can be maintained by general commodity haulers according to standards the market will support.

But it is easy to overdraw this gloomy picture. Aside from the cushion of constantly-expanding transport demand, the motor carriers have much captive traffic from new plants without direct access to rail facilities, would gain volume from the private and exempt sectors with the erosion of the high value-of-service rates, and would commonly share many markets on the strength of their common service and occasional cost advantages. While perhaps more vulnerable, the water carriers are protected by their toll-free use of publicly-provided right-of-way. Since the rail overhead burden arises largely from the investment associated with privately-provided fixed facilities, the "full" costs of water carriers closely corresponds conceptually to railroad out-of-pocket cost.

The contemplated pricing system would involve lower costs, lower prices, and smaller investment requirements for present output levels and would encourage a more rational pattern of future investment for output expansion. A market-oriented system of competitive prices would appear to yield revenues adequate to support the quantity and quality of service required with a minimum of redundant capacity.

\footnotetext{
${ }^{25}$ It is certainly vital, however, that any such liquidation be preceded by the kind of regulatory reforms contemplated here to avoid too severe cutbacks that would scrap facilities more efficient than some that were continued in production. For a stimulating discussion of the technical and cost potentialities of railroads with adequate traffic to nourish them, see JoHN W. BARRIGER, SUPER-RAILronds For a Dynamic American Economy (1956).

${ }^{53}$ For empirical investigations of the relationship between motor-carrier size and efficiency, see Roberts, Some Aspects of Motor Carrier Costs: Firm Size, Efficiency, and Financial Health, 32 Land Econ. 228 (1956); Robert A. Nelson, Motor Freight Transport for New England (New England Governors" Comm. on Public Transportation Rep. No. 5, 1956).
} 


\section{Applicability of the Model}

Assuming the beneficent results ascribed to price competition, a very important question is whether it might be expected to show in practice the admirable characteristics described in the model. Its real-world applicability depends largely on the validity of the crucial assumptions employed: pursuit of the profit-maximization goal, an approximation of traditional demand functions, and reasonably accurate command of basic market data.

The profit-maximization goal is not always relentlessly pursued by business generally. Professors Baumol and Lanzillotti independently identify common adherence to other goals, such as total revenue maximization consistent with realizing some predetermined rate of return less than the maximum attainable. ${ }^{54}$ It may be that nonoptimizing goals influence railroad pricing policy, although such forces must be mitigated by the inability of many companies to earn what is generally regarded as a normal return. An emphasis on largest attainable volume is consistent with historically-chronic underutilization and the implicit assumption that profit interests are best served by the largest possible volume of business (a generalization of limited validity). Such an emphasis would be strengthened by railroad organization which typically places pricing authority and sales in the hands of the same executive, who is more readily judged by favorable volume trends (his sales effort) than by the judiciousness of his pricing policies. But regardless of past policies, there is growing evidence of increasing railroad emphasis on maximizing net revenues. Statements of railroad spokesmen in the hearings cited above and in public addresses recurrently emphasize efforts to improve this financial measure. With railroad earnings as they are, an active pursuit of profit-maximization may be expected as a result of new pricing insights developed from the highly intensified interest in market research.

The frequency in Commission cases of altered volume and market shares in response to changed price relationship attests to the essential validity of the demand function assumption in typical markets involving rail-motor competition. Since this demand condition is facilitated in markets with numerous shippers, it is significant that virtually all of the important competitive rate adjustments since $195^{\circ}$ have been applied on a region-wide basis. But there are probably some markets, particularly in the rail-water competitive arena, that consist of one shipper who will not divide his traffic or of a small number of shippers who react identically to specific price relationships. But such "all or nothing" markets are ruinous only if prices are driven down to levels approaching the direct costs of the low-cost carrier because of narrow cost differentials or compensating service advantages." With a reasonable margin between the high and low costs and without offsetting quality considerations, the result will approximate that suggested in case three, where competitive stability is achieved from foreclosure of the disadvantaged rival at nonruinous rates. Although extensive empirical research would be desirable, it does not

\footnotetext{
"Baumol, On the Theory of Oligopoly, 25 Economica 187 (1958); Lanzillotti, Pricing Objectives in Large Companies, 48 AM. Econ. Rev. 921 ( $x_{95} 8$ ).
} 
seem probable that "all or nothing" markets with ruinous attributes are sufficiently significant to condition general policy.

Obtaining adequate knowledge of costs and demand to achieve pricing goals is a general problem plaguing all industries. Although transport companies have not been aggressive in developing techniques to gain these insights, the railroads, whose actions are most crucial for price competition, are now more heavily committed to developing market information. Certain facilitating circumstances make the achievement of a working knowledge of market structures easier for transportation companies than for those in most other industries. Industry efforts profit from the cost research of the Commission's staff and from the traffic flow and rate data provided in the waybill summaries. Because of the detailed reporting requirements imposed on regulated industries, these companies have an unusual opportunity to develop data regarding rivals' operations. The forum provided by the rate bureaus is valuable for eliciting information regarding customer reactions to specific price relationships. Furthermore, the legitimacy of group-pricing may itself be significant in permitting an intimate pooling and evaluation of information. Finally, the calculus itself may be simpler than for industry generally, since transport companies can measure total market size more easily than producers of consumers' goods who compete for dollars with a whole spectrum of alternatives.

The evidence seems rather convincing that transport markets can be expected to perform sufficiently closely to the model to permit effective price competition. Perfection, a virtually unattainable goal in pricing problems, is not essential; stability requires only reasonably competent management efforts to serve the interests of their companies. The attainability of the stability requirements and the magnitude of the advantages of a market-oriented system of competitive prices warrant the conclusion that present regulatory restraints are not in the public interest.

\section{IV}

\section{The Appropriate Role of Regulation}

Policy decisions regarding transport competition should reflect the rather generally-accepted presumption underlying our free-enterprise system that reasonably effective market controls are superior to government controls, which should be instituted only on the basis of a clear showing that they are required in the public interest. Controls should be undertaken only to preserve and strengthen the system; any gratuitous intervention not directed to this end saps its strength. The evidence is persuasive that such controls over transport competition are not required and are actually detrimental, indicating the need for drastic limits on the scope of regulation.

Although a withdrawal of regulation from the general administration of price competition would serve the public interest, two problem areas require special consideration. The first is the instability that may arise in "all or nothing" markets. 
Although probably not sufficiently serious to condition general policy and justify present controls over all price competition, this problem should not be ignored. It calls for extensive investigation to determine the relative importance of markets where cost and service relations are apt to dictate close encroachment of rates on the out-ofpocket costs of the low-cost carrier. Perhaps formal measures could be devised to identify such special situations requiring regulatory floors. This departure from basic policy should be based on a clear-cut indication of significant revenue-eroding effects of such markets.

The other problem in a system of pricing freedom is the prevention of truly destructive competition reflected in predatory actions designed to destroy a rival with less staying power by intentionally suffering short-term losses. Regulation should be held ready to deal with these situations by the exercise of antitrust techniques if they should arise. Although such pricing policies pose difficult control problems that have not yet been effectively solved, the simple recognition that restraint should be applied to this behavior and not to all price reductions would signify an important advance in transport control. An imperfect but reasonably adequate test to identify predatory action is the establishment of rates below direct costs. Consideration might be given to applying generally the statutory rule covering rail-water competition by placing ceilings on rates that fall below a certain minimum to prevent their increase if the competition is destroyed.

These two areas represent aberrations from the general case of workable price competition. More important than its restrictive efforts in these situations is a second basic function of regulation: to help make competition work through counsel and research. This function, commonly performed by government in such areas as agriculture, commerce, and labor, entails further cost and market research to assist the carriers with their pricing problems. If it would provide comfort to the skeptics, it might be desirable in specified cases of sufficient magnitude to continue the hearings process as a compulsory forum for pooling cost and market information among all competitors on the theory that public carriers are not entitled to closelyguarded secrets as are business firms generally. Regulation can also assist in making competition workable by providing more rate flexibility through relaxing tariff publication requirements. More liberal experimentation has obvious advantages in pointing the direction toward equilibrium adjustments. Although businesses value stability in all factor prices, rate stability bordering on rigidity is held in uncommonly high regard even where transport outlays are not of major importance. In other sectors of the economy, inflexibility is not an important criterion of price validity.

This view of price competition and the limited role of regulation suggests that public control should concentrate on upper rate limits, the historic function which it is reasonably well-equipped by experience, temperament, and technique to undertake. As previously emphasized, the real problem of the monopolistic value-of-service rates is that they will be maintained by tacit collusion, and not that they will be reduced by competition and cast a fictitious burden on segments of the shipping public. 
Although adequate market insights and pursuit of the profit motive may spotlight situations where it is to the competitors' mutual advantage to let well enough alone, such rates violate the competitive equilibrium and are unjustified in a competitive pricing system. Instead of being protected, such rates should be forced down by regulation as a facet of making competition work.

The envisioned system is designed, furthermore, to maximize profits in individual markets. Although the competitive orientation differentiates it from pricing by monopolistic utilities and imposes substantial earnings limitations, the unevenness of competition, along with tacit collusion, may permit excessive returns. This possibility emphasizes the importance of the historic regulatory function of earnings control, particularly since, unlike duopoly or oligopoly markets generally, price increases are often matched. With railroads in the price leader's role, rate increases occasioned by generally rising prices are not uniform among all markets under the differential pricing system. The price followers tend to increase rates according to the same pattern and often by the same amounts to produce matched increases.

The enterprise system places substantial faith in the virtues of market-oriented prices to dictate benevolently the total output of various goods and services, the flow of investment funds into the respective industries, and the financial fortunes of individual producers. The fact that transport services are regarded as vital for the country's commerce and defense does not in itself render the basic principles inapplicable to these industries; in fact, regulatory departures from these principles weaken the system by denying the ultimate authority of the market place, a sin of which present control is eminently guilty. Successful thwarting of market forces cannot be accomplished in a half-slave and half-free system, but only by substantial extension of control. The forces of regulation are in disequilibrium and must go one way or the other. This ballot is cast for market-orientation as the approach best calculated to serve the public interest as measured by social efficiency, equity, and an optimum transport system. 